\title{
Vontade de presença, vontade de corpo: para pensar o teatro brasileiro contemporâneo
}

\section{Resumo}

Este texto propõe pensar o teatro brasileiro contemporâneo a partir da perspectiva dos Estudos da Presença. Problematiza-se o contorno de três termos: teatro, brasileiro e contemporâneo. Defende-se a ideia de vontade de presença como catalisadora de determinados aspectos do teatro contemporâneo no Brasil, descrevendo alguns acontecimentos da cena teatral desde a década de 1980. O artigo discute a cena contemporânea brasileira a partir de elementos como o corpo e a presença.

Palavras-chave: Estudos da Presença; Corpo; Teatro Contemporâneo; Teatro no Brasil.

\section{Abstract}

This paper proposes to think Brazilian contemporary theatre from the viewpoint of the Studies on Presence. The author problematises the definitions of three words: theatre, Brazilian, and contemporary. The work defends the idea of will to presence as a catalyst for certain aspects of contemporary theatre in Brazil, describing some events in the theatre scene since the 1980s. The article discusses the contemporary Brazilian scene based on elements such as the body and presence.

Keywords: Body; Contemporary Theatre; Studies on Presence; Theatre in Brazil.

Nada pode ser mais difícil do que apreender ou apresentar culturas tão distintas, multifacetadas e evadidas do que as culturas que formam o Brasil, adicionando a isso a dificuldade de reter, mesmo que por um único instante, o inapreensível do fenômeno teatral.

Ocorre, ainda, que aquilo que chamamos Teatro Brasileiro não é nada além de uma unidade ${ }^{2}$ historicamente arbitrária e politicamente friccionada entre uma multifacetada gama de práticas performativas ${ }^{3}$, das quais ora incluímos, ora excluímos

1 Gilberto Icle é doutor em Educação pela Universidade Federal do Rio Grande do Sul (UFRGS), na qual é professor no Programa de Pós-graduação em Educação e coordena o GETEPE-Grupo de Estudos em Educação, Teatro e Performance www.ufrgs.br/getepe. Ele coordena e atua, ainda, na UTA-Usina do Trabalho do Ator, grupo de pesquisa e produção de espetáculos www.utateatro.com. É editor-chefe da Revista Brasileira de Estudos da Presença www.seer.ufrgs.br/presenca e bolsista de produtividade do CNPq (Nível 2).

2 Tomo aqui, evidentemente, o sentido de unidade em Michel Foucault. Para o filósofo francês trata-se de aplicar a noção de descontinuidade, pois "[...] as unidades que é preciso deixar em suspenso são aquelas que se impõem de maneira mais imediata [...]" (Foucault, 1969, p.35, tradução do autor), trata-se, portanto, das unidades com as quais estamos acostumados e mesmo as que naturalizamos.

30 conceito de "práticas performativas" visa a escapar do etnocentrismo e do aparente conforto que a palavra teatro engendra, alargando as possibilidades daquilo que incluímos na cena. Veja essa discussão em Pradier (2001). 
determinadas manifestações, e nossa operação de nomear o mundo. A historiografia brasileira elegeu o teatro produzido nas megalópoles brasileiras (Rio de Janeiro-RJ e São Paulo-SP) como o centro e, em muitos casos, o exemplo privilegiado do que seria o teatro brasileiro, desconsiderando a produção periférica (ou fabricando a ideia de que se trata de produção da periferia). Os exemplos são muitos, basta tomar os livros sobre História do Teatro Brasileiro e veremos que são raras as menções a espetáculos e artistas que trabalham fora do eixo (RJ-SP), mesmo levando em consideração a numerosa produção desses centros. O termo Teatro Brasileiro acaba por aderir a uma postura regionalista e etnocêntrica, nomeando a história e a crítica teatral das cidades do Rio de Janeiro e de São Paulo como sendo a história e a crítica do teatro brasileiro. Trata-se de nomear uma história como a história.

Além disso, estudos distintos, nos últimos anos, mostram a dificuldade em delimitarmos mesmo a mais naturalizada das unidades com as quais convivemos: o termo teatro. Essa noção deixou de ser para os Estudos Teatrais o centro e o nó por intermédio do qual encontraríamos um abrigo seguro para dela extrair a base de nossas pesquisas. O termo foi colapsado pelos Performances Studies (SCHECHNER, 2002) na intersecção do experimentalismo e da antropologia; foi novamente eivado de nuances e completamente destruído e substituído (por práticas performativas) nas formulações da Etnocenologia (PRADIER, 1997); alargado e adjetivado no que Lehmann (2002) chamou de teatro pós-dramático. Tais mudanças são, com efeito, apenas um reflexo das práticas cênicas brasileiras que nos últimos anos insistem em mesclar teatro e dança; performance e ritual; ópera e circo; manifestações de rua e de sala; entre inúmeras outras possibilidades.

A essa dificuldade se agregam outras, por exemplo, o reconhecimento das identidades que caracterizariam o Brasil ou aquilo que poderíamos nomear como a brasilidade do teatro brasileiro. Se caminhamos em terreno movediço no que concerne aos termos teatro e brasileiro, a expressão contemporâneo não deixa de ter ela própria dificuldades contundentes: o que seria o contemporâneo? Referir-se-ia àquilo que nos é temporalmente coincidente? Ou colocaríamos no mesmo conjunto práticas inovadoras e, de certa forma, ao menos um pouco up to date em relação ao nosso próprio tempo?

Como explorar, então, três termos tão relativizados, tão perigosos? Quais espetáculos, práticas, movimentos, grupos e companhias, fariam parte dessa discussão?

Obviamente não me resta outra alternativa senão escolher um foco, um olhar por intermédio do qual mostrar a complexidade do que chamamos teatro brasileiro contem- 
porâneo e o faço sabendo dos riscos a que me submeto. Portanto, ao invés de lhes apresentar aqui uma síntese das principais correntes e das principais práticas que, de uma vez por todas, caracterizariam o teatro brasileiro no que ele tem de contemporâneo, optarei por escandir alguns elementos e o farei a partir de uma noção bastante duvidosa: a de vontade de presença.

As sociedades brasileiras, ao menos aquelas sociedades urbanas e globalizadas, nas quais gira a maior parte da produção dita teatral, tendem a um movimento de virtualização das relações. As tecnologias da informação e da comunicação produzem, cada vez mais rápido, condições de afastamento das pessoas: podemos nos comunicar, comprar, namorar, estudar, à distância. Evidentemente, nos beneficiamos de uma facilidade de comunicação e contato virtual que aduz a uma proximidade, ainda que virtualizada. Ao mesmo tempo, quanto maior é nossa mobilidade, quanto mais afastamos os corpos uns dos outros, mais sentimos vontade de estar próximos, de estarmos em presença de outras pessoas, de sentirmos a presença de coisas distantes no espaço e no tempo, mais temos vontade de presença.

Assim, o que tomamos aqui como presença é menos aquilo que se tornou comum no jargão teatral, - a força ou a qualidade atrativa do ator -, e mais o universo do que escapa à linguagem, ao sentido, à significação. Esse tipo de discussão encontra-se desenvolvida naquilo que nomeei como Estudos da Presença ${ }^{4}$.

Por isso, a ela agregamos o termo vontade ${ }^{5}$, compreendido como um movimento, um sintoma que nosso teatro sabe bem expressar e o soube nas últimas décadas.

Parece-nos que justamente um teatro que podemos dizer contemporâneo irrompeu nas artes da cena brasileira nos últimos anos. Pois que dentre as práticas diversas e multifacetadas que conhecemos no Brasil, alguns artistas da cena tiveram a coragem de explicitar essa vontade de presença e, nesse sentido, trata-se de exemplos esparsos, pois "os contemporâneos são raros. É exatamente por isso que ser contemporâneo é, antes de tudo, um trabalho de coragem" (AGAMBEN, 2009, p.30, tradução do autor).

O que tais práticas cênicas fazem emergir de corajoso é a tendência de problematizar as artes da cena como um lócus privilegiado para exercer uma atividade bastante humana: estar em presença do outro.

\footnotetext{
4 Trabalhos mais aprofundados sobre essa questão podem ser encontrados em Icle (2011, 2012a; 2012b).

5 O termo vontade de presença, aqui empregado, faz, evidentemente, referência ao conceito de "vontade de potência" de Friedrich Nietzsche. Para o filósofo alemão, a "[...] vontade de potência não é um ser, não é um devir, mas um pathos, ela é o fato elementar de onde resulta um devir e uma ação [...]" (Nietzsche, s.d., p.242).
} 
Evidentemente, não podemos separar o que Hans Ulrich Gumbrecht chama de "efeitos de presença" do que nomeia como "efeitos de significação"6 (2010, p.40). A própria experiência estética, que o autor alemão prefere traduzir como "momentos de intensidade" (2010, p.151), é sempre uma oscilação entre presença e significação. No entanto, podemos ver, ainda em sua companhia, um predomínio em determinadas culturas sobre uma ou outra.

Nesse caminho, é claro perceber que vivemos numa era hermenêutica, na qual a interpretação, como processo de acesso à verdade recôndita, é o grande procedimento de decodificação que justifica nossa ação. O corpo, portanto, nessas culturas da significação é tido como obstáculo, como aquilo que impede o acesso à profundidade, esta última, assim, plano que esconde os significados. A interpretação seria, então, na descrição do filósofo alemão sobre a cultura da significação, a operação privilegiada que traz da profundeza os significados que são gestados não na própria materialidade, jamais no corpo, mas sempre em algum lugar outro que chamamos mente, espírito, alma.

As sociedades europeias na longa tradição racionalista são exemplares nessas culturas da significação, pois tomam esse plano hermenêutico como guia hegemônico das formas de experimentar o mundo.

O Brasil, entretanto, ainda que embebido desse racionalismo, conserva - ou melhor seria dizer cria - culturas que têm na presença o cerne de sua existência. Não se trata de imaginar uma presença pura, um vazio de significação, mas antes, um predomínio da corporeidade como forma de experimentar o mundo, na qual a atenuação que a significação faz no impacto dos corpos está menos evidente.

Algumas culturas que formam o Brasil se apoiam, ainda, em muito numa corporeidade explícita e na sua imensa complexidade e paradoxalidade que, em muitos casos, instiga. Como nos diz o brasilista François Laplantine

O que nos encanta nos latino-americanos, é [...] sua capacidade de serem ocidentais e não ocidentais, intelectuais e sensuais, modernos e tradicionais, ateus e religiosos, crentes e pagãos, racionais e sentimentais, críticos e líricos e, às vezes, tal qual a imagem de Macunaíma, anti-herói do livro homônimo de Mario de Andrade (Macounaïma, 1928), honestos e mentirosos. (LAPLANTINE, 1997, p.33)

Todas essas contradições que aduzem à imagem basilar de Macunaíma, correspondem na vida cotidiana contemporânea a esse leque infinito de matizes, matrizes, e

6 Na tradução brasileira do livro de Gumbrecht o termo foi traduzido como "efeitos de sentido". Eu prefiro traduzilo como "efeitos de significação" ou "efeitos de significado", para acompanhar de maneira mais precisa a tese do autor segundo a qual haveria uma diferença entre linguagem e presença. 
condizem com as poéticas da cena em nosso país. Macunaíma é, aliás, incontornável para se compreender em que o teatro brasileiro se relaciona com a vontade de presença.

Primeiro, porque o romance foi base de uma das mais importantes encenações das últimas décadas, dirigida pelo célebre Antunes Filho com o grupo Pau-Brasil. Estreado em 1978, o espetáculo deu origem ${ }^{7}$ a uma carreira forte e a um tipo de encenação que fez do diretor o criador de "espetáculos antológicos" (FERNANDES, 2013, p.332). A síntese que o espetáculo atingia vinha da forte visualidade e do trabalho centrado, ao mesmo tempo, nos atores.

Os coros, os corpos nus, os blocos, a extraordinária plasticidade, a lentidão, o impressionismo, o minimalismo, lembram as encenações de Bob Wilson, Kazuo Ono e Tadashi Suzuki. Não obstante a crítica explícita que o anti-herói Macunaíma apresentava, a encenação propõe ao público momentos de intensa magnitude, de poesia que não pode ser medida somente a partir do plano do significado. Os corpos nus ilustram - para além de personificarem as figuras do romance de Mario de Andrade -, a função espacializante da encenação, um tipo de relação com o público que rompe com as poéticas militantes de seu tempo.

Tratava-se de uma encenação corajosa e audaz. Dela se originaram uma série de possibilidades para a cena teatral brasileira, nela se resumiam uma brasilidade paradoxal.

A segunda razão é porque a figura de Macunaíma é exemplar nisso que a encenação de Antunes Filho nos lega como uma experiência da contradição. Macunaíma é a encarnação da contradição brasileira. "O desfecho das reviravoltas de Macunaíma ilustra a impossibilidade de escapar das contradições e dos dilemas de um duplo pertencimento" (GRUZINSKI, 1999, p.21, tradução do autor). Macunaíma, portanto, é personagem, mas é também ícone do teatro no Brasil. Ele é nativo e europeu e na sua força transformadora põe à mostra o corpo brasileiro, aquele mesmo corpo descrito como gingado (LAPLANTINE, 2009), balançado, como um quebra-requebra das cadeiras. Ele impõe, então, uma presença no seu traço sensual. Sensualidade brasileira que é um modo de experimentar o mundo que não encontra parâmetro nas significações, é materialidade mesma. A sensualidade, no teatro ou na vida, é matéria significante, não pode ser significada, ou ainda, significá-la não nos ajuda a experienciá-la.

7 Trata-se ainda de sublinhar que se trata de origem e não de início, pois a carreira desse artista havia começado antes dessa encenação. 
Esse traço da cena no Brasil liga-se à corporeidade e a materialidade da ação propriamente dita como elemento fundante, como objetivo e como resultado das investigações cênicas e performáticas das últimas décadas. Matizada em inúmeras possibilidades, mesclada com outras práticas, misturada aos elementos do teatro tradicional no qual o texto dramático é o ponto de partida e a referência maior da cena, essa vontade circunscreve hoje e nas décadas que nos precedem, especialmente desde os anos 1980, um sem número de poéticas cênicas brasileiras.

Os exemplos históricos dessa vontade de presença no teatro brasileiro não cessam de aparecer desde muito. Antunes Filho ajudou a caracterizar a década de 1980, como um momento de afirmação da figura central do diretor, a qual foi protagonista de um movimento de reencaminhamento da militância política, característica da década anterior na qual o Brasil estava mergulhado numa forte ditadura militar, para um abstracionismo mais estético. "O contexto de liberalização política desfaz, aos poucos, o teatro de resistência que se criara na oposição ferrenha à ditadura militar e se fundava em alusões veladas à situação de opressão" (FERNANDES, 2013, p.335), dando espaço para outras experimentações, mais centradas na linguagem teatral. Não obstante tal movimento, o teatro político engajado, de matriz brechtiana, não deixou de existir, permanecendo nos palcos brasileiros na herança dos trabalhos, por exemplo, de Augusto Boal (1931-2009).

Esse movimento de alargamento das possibilidades estéticas e poéticas da cena brasileira se fez acompanhar de certo estabelecimento de diferentes modalidades de mercado teatral. Se no eixo Rio-São Paulo se estabelecem companhias mais estáveis e temporadas longas, em outras capitais do país como, por exemplo, em Porto Alegre, Salvador, Belo Horizonte, os grupos, em sistema de cooperativa de atores, não apenas afloram aqui e acolá como se multiplicam, criando um sistema de produção teatral que mistura espetáculo, intervenção comunitária, pedagogia, entre outras atividades teatrais e parateatrais na intenção de poder sobreviver aos apelos de uma economia cada vez mais liberal. O teatro brasileiro exercita, pois, aquilo que Stanislávski já havia marcado como a separação entre espetáculo e teatro, o segundo sendo bem mais amplo que o primeiro (RUFFINI, 2004).

Nesse sacudir da cena, na construção de uma cultura teatral mais alargada do que o espetáculo, a figura lendária de José Celso Martinez Correia atravessou, desde a década de 1960 (anos de intensa militância e denúncia da ditadura militar) aos dias 
atuais, o panorama do teatro no Brasil. O período a partir da década de 1980 se caracteriza por uma intensa produção junto ao Teatro Oficina em São Paulo, com o qual, renomeado para Teatro Uzyna Uzonå ${ }^{8}$ investigou a linguagem teatral na sua interseção com o ritual. Dele, do ritual, Zé Celso captura a corporeidade para um embate permanente com a indústria cultural. Tal fricção tem no trabalho grupal a ritualização necessária para uma crítica contundente da cultura brasileira, traço que procura restabelecer o corpo no cerne da atividade teatro-ritual. O seu Ham-let de 1993 é exemplar no que diz respeito ao trabalho do ator, pois o personagem principal é atuado por Marcelo Drummond com uma "[...] interpretação histriônica, distante das reflexões intelectuais que ocuparam centenas de estudiosos [...]" (FERNANDES, 2013, p. 351) e, portanto, muito mais interessado no impacto físico da atuação.

Zé Celso, assim, desde a célebre montagem de O Rei da Vela (1967), texto de Oswald de Andrade, que marcou o teatro brasileiro como representante de um teatro antropofágico, não cessou de ser contemporâneo. Não cessou de criar "culturas da presença", colaborando para um teatro tanto mais crítico, quanto carnal; tanto mais alinhado a seu tempo, quanto avant-garde. Em vários sentidos ele tem sido um contemporâneo, pois

Aqueles que coincidem plenamente com sua época, que se adaptam perfeitamente a ela em todos os pontos, não são contemporâneos, pois por essas mesmas razões, eles não chegam a olhar seu próprio tempo. Eles não podem enxergar sua época (AGAMBEN, 2009, p.25, tradução do autor).

Se Zé Celso e Antunes Filho apareceram como fortes figuras no teatro contemporâneo, eles ajudaram, ainda, a tornar a década de 1980 o momento privilegiado da ascensão de grandes encenadores brasileiros. Mas se essa época foi o fortalecimento da figura do encenador - como é o caso dos trabalhos de Gerald Thomas, Maria Helena Lopes, Ulysses Cruz, Gabriel Villela, Márcio Vianna, Bia Lessa, Moacyr Goés, Márcio Aurélio, Beth Lopes, - apenas para citar alguns daqueles que este autor teve a oportunidade de ver à época -, ela foi, também, o início da solidificação de um teatro grupal, no qual o ensemble tomou o protagonismo tanto na forma de produzir e manter grupos estáveis, como no estabelecimento e desenvolvimento de poéticas que somente podem ter lugar a partir de relações artísticas longevas. Entretanto, como é sempre característica do Brasil, não se trata bem de um dualismo de modelos, mas de uma mistura, às vezes paradoxal. Esses dois modelos se fundem (elencos dirigidos 
por grandes encenadores e grupos com identidades artísticas bem marcadas), se sobrepõem, possibilitando uma mistura tipicamente brasileira, pois tais paradoxos irão

Conectar aquilo que na boa lógica cartesiana seria excludente, e mais ainda o fato de que essa mistura não se estabeleça como confusão e que se possa viver sem uma separação esquizofrênica, uma dupla, tripla, quádrupla identidade, é frequentemente desconcertante (LAPLANTINE; NOUSS, 1997, p.33-34, tradução do autor).

A partir desses inúmeros modelos, as décadas de 1990 e 2000 vão se multifacetar numa gama quase infinita de poéticas. Impossível seria uma descrição precisa dessa variabilidade.

No que concerne à vontade de presença, esses momentos do teatro brasileiro dão conta da centralidade do corpo, do trabalho do ator como gestor e ponto nodal da criação artística para a cena, tendo no que se convencionou chamar Teatro de Grupo um ancoradouro tenaz.

O Teatro de Grupo é, no Brasil, uma modalidade variável, com centenas de grupos que se auto-identificam com tal denominação. Grosso modo, esse tipo de coletivo funciona em regime de colaboração, seja nos aspectos artísticos, seja nos aspectos da produção. A união e o trabalho partilhado servem, assim, para uma existência mais fortalecida, mas, também, para o estabelecimento de poéticas específicas que, em muitos casos, funcionam como a constituição de identidades artísticas singulares.

Atualmente, o país tem centenas de grupos, muitos com mais de vinte anos de existência. Esses coletivos centram-se nos próprios atores, na sua gestão administrativa e nas suas concepções cênicas. Podem ou não possuir um diretor fixo ou convidar um diretor externo ao grupo (são os atores, de certa forma, que contratam um diretor que permanece com o grupo apenas para uma determinada encenação). O longevo grupo mineiro Galpão é um exemplo clássico desse tipo de funcionamento, tendo variado desde a década de 1980 diferentes modos de funcionamento. O trabalho do grupo com o diretor Gabriel Villela em 1992 para a montagem de rua baseada em Romeu e Julieta e a encenação seguinte de 1994, A Rua da Amargura - 14 passos lacrimosos sobre a vida de Jesus, coroam esse tipo de parceria e mistura entre um grupo consolidado e um diretor externo ao grupo. Há ainda grupos que se sustentam como grupo, mesmo tendo uma figura central de um diretor como, por exemplo, o Ói Nóis aqui Traveiz, de Porto Alegre, que é liderado por Paulo Flores. Entretanto, antes de funcionar como uma companhia na qual a liderança é do diretor, o Teatro de Grupo - a exemplo do Ói Nóis - se caracteriza, de modo geral, como um 
espraiamento das lideranças internas e das decisões que são tomadas muito mais em regime coletivo.

Assim, o estudo do trabalho desses grupos mostra que é a colaboração ${ }^{9}$ entre os diferentes artistas e a mobilidade das funções de ator e diretor (em muitos casos, também, de cenógrafo, figurinista, iluminador, diretor musical; uma vez que são alguns atores que desempenham tais funções) que torna o Teatro de Grupo o que ele é. Exemplos extremos desse tipo de funcionamento se dão em grupos sem diretor como é o caso do LUME de Campinas, desde que Luiz Otávio Burnier, seu criador, faleceu precocemente em 1995.

Esse tipo de vida artística e esse modo de produção enfatizam, portanto, o corpo do ator como centro por intermédio do qual todo o resto se produz. Corpo que implica, assim, uma vontade de presença própria da prática cênica brasileira. Paradoxal, tal prática contempla, em muitos casos, um pêndulo que oscila entre um tipo de criação mais racionalista, crítica e reflexiva e um tipo de criação menos preocupada com os sistemas de significação da cena.

Seja como for, o Teatro de Grupo no Brasil constitui não apenas um simples modo de operação poética e administrativa das entidades teatrais, mas, também, um movimento político, por intermédio de associações e organizações não governamentais que lutam pelos direitos, conquistas e avanços nos domínios das políticas públicas (sobretudo de financiamento) para um tipo de produção cênica que se distancia do modelo das grandes empresas (mais encontrados nos grandes centros urbanos) e privilegia, portanto, o trabalho mais artesanal e experimentalista.

O paradoxo brasileiro se faz, mais uma vez, presente nesse tipo de produção, pois se há nela um traço de presença (de uma prática que não se articula necessariamente na reflexão puramente racional), ela não deixa de ser, ao mesmo tempo, vontade de presença e vontade de reflexão lógica.

É por isso que a produção teatral brasileira é singular na sua relação com a universidade e o teatro de grupo, particularmente, tem um atravessamento peculiar no que diz respeito à produção de conhecimento no contexto universitário no Brasil.

Não havendo, senão raramente, escolas de formação ao modo dos conservatórios europeus, é na universidade que atores e diretores de teatro se formam. Essa característica implica, então, duas outras: 1) que esses cursos são técnico-práticos,

9 Para profundar a noção de "processos colaborativos" como forma de existência das poéticas cênicas brasileiras, veja os trabalhos de Silvia Fernandes (2010) e Stela Fischer (2010), entre muitos outros. 
comportando muitas horas de improvisação teatral, técnicas de atuação, técnicas de encenação, trabalho corporal e vocal, complementados por uma parte teórica; 2) que o perfil de grande parte dos professores desses cursos de formação é o de artistas da cena que são, ao mesmo tempo, pesquisadores, professores e artistas.

Como práticos, esses professores fazem uma dupla ligação entre teatro e universidade. Eles próprios são, de um lado, em muitos casos, atores e diretores importantes da cena brasileira e, por outro, formam boa parte, senão a maioria, dos trabalhadores da cena (atores, diretores, cenógrafos, figurinistas e outros profissionais da cena).

O amálgama com a universidade produz, também, um engajamento dos grupos de teatro com a formação de novos artistas e com as intervenções em comunidades hipossuficientes economicamente. Essa mistura entre cena, pedagogia e reflexão caracteriza de certo modo boa parte do que se produz no país, pois as universidades que oferecem formação artística para o teatro e a dança estão espalhadas por praticamente todo o território nacional. Esses cursos funcionam em muitas cidades como centros propulsores da produção teatral e coreográfica.

Muitos grupos, portanto, possuem diferentes ligações com a universidade ${ }^{10}$, seja porque seus integrantes formaram-se nesses cursos, seja porque alguns deles são ligados às universidades que Ihe dão acolhimento. Assim, o trabalho do LUME de Campinas é, por exemplo, um núcleo de investigação da Universidade de Campinas, assim como o grupo de Antônio Araújo tem ligações com a Universidade de São Paulo, sendo ele professor nessa instituição. O meu próprio trabalho em Porto Alegre, com a UTA-Usina do Trabalho do Ator ${ }^{11}$, possui uma ligação com a Universidade Federal do Rio Grande do Sul, pois a maioria de nós somos professores nessa universidade e o trabalho do grupo gira em torno das pesquisas ali realizadas.

Essa relação com a universidade e uma busca constante de práticas e teorias estrangeiras se une na cena, mas, em especial, na pedagogia que forma os profissionais. Essa mistura que aportou ao Brasil uma fusão entre princípios herdados de reformadores europeus como Etienne Decroux, Jacques Lecoq, Jerzy Grotowski, Eugenio Barba, entre outros; e práticas brasileiras como capoeira, candomblé, folguedos,

10 Segundo Jacó Guinsburg e Rosangela Patriota "os cursos de formação de atores, em diversas regiões do país, foram fundamentais para aqueles que ingressaram no teatro na segunda metade do século XX. Porém, com a criação dos cursos de Artes Cênicas, em nível superior, intensificou-se o diálogo entre teatro e universidade" (2012, p.221)

11 Para maiores informações sobre esse grupo consulte www.utateatro.com ou ainda os trabalho de Pereira (2012), Massa (2012) e Lisboa (2012). 
dança de rua, danças populares (apenas para citar algumas); engendrou uma cena plena de corporeidades. Um exemplo clássico dessa cena mestiça é o trabalho do ator e performer nordestino Antônio Nóbrega.

Isso não significa dizer que nosso teatro relegou a segundo plano o texto ${ }^{12}$ e a oralidade, muito antes pelo contrário, a encenação de grandes clássicos e a adaptação de romances e outras formas literárias para a cena estende-se ao longo das últimas décadas como uma verdadeira opção da cena no Brasil. Seria impossível listar apenas alguns exemplos. A tradição da contação de história, do causo, da narrativa, do rapsodo é, da mesma forma, bastante presente.

Seja como for, as práticas teatrais desses conjuntos brasileiros parecem, sobretudo a partir do início da década de 1990, tender a uma atenção ao corpo. O que isso significaria? Não se trata de imaginar um teatro dançado ou coreografado, embora a mistura com o que normalmente chamamos dança, é explícita numa série de trabalhos que na cena contemporânea brasileira não podem ser classificados nem como dança, tampouco como teatro, se tomamos essas palavras num sentido mais tradicional.

Olhar a vontade de corpo da cena brasileira seria apenas enfatizar um traço singular que se pode reconhecer de formas diversas, mas, sobretudo, numa certa materialização do corpo. Num aspecto que mobiliza o corpo não apenas como suporte de um personagem, mas, também, como materialidade específica, como presença no espaço. Tratar-se-ia da constituição de uma teatralidade "que prioriza a materialidade vocal e corporal do ator e os meios especificamente cênicos de composição" (FERNANDES, 2013, p. 347).

Esse tipo de relação é, sem dúvida, pautada de maneira mais enfática na cena brasileira a partir do momento em que aquilo que chamamos performance ${ }^{13}$ atravessou, para não dizer estilhaçou, a cena no Brasil.

Inúmeros trabalhos vão reconhecer, assim, certas "hierarquias do real" (RAMOS, 2011, p. 61), propondo à cena desde personificações clássicas que fazem desaparecer a personalidade do ator, na interpretação de um personagem, até o desnudamento de elementos pessoais do performer e ações mais despidas de qualquer efeito de ilusão.

Se a performance, de certa forma, descontrói a cena em muitos trabalhos contemporâneos, o uso de espaços não teatrais ajudou a colapsar os modelos mais

12 Para um aprofundamento das relações entre cena e texto veja o trabalho de Bulhões-Carvalho (2010).

13 É preciso aqui lembrar o pioneirismo no trabalho sobre a Performance no Brasil de Cohen (2011). 
tradicionais da cena. A ocupação de galpões, igrejas, hospitais, casas, apartamentos e, em especial, a produção elaborada para a rua ou espaços abertos, têm constituído um modo não apenas de resolver a carência de espaços teatrais, mas também de produzir poéticas singulares para a cena e a performance.

Corpo e presença poderiam, enfim, constituir um olhar (dentre inúmeros outros) para sobrevoar a cena contemporânea, mas ainda constituem uma vontade de estar com o outro, de compartilhar. Talvez pudéssemos reconhecer nesses elementos os vestígios de certas práticas que como simultâneas a nós mesmos são difíceis de perceber; talvez presença e corpo, "na sua assustadora carnalidade" (AZEVEDO, 2009, p.128) sejam os elementos por intermédio dos quais podemos acessar aquilo que a cena tem de obscura, ainda informe; na brasilidade dos corpos, na presentificação singular de nossos movimentos, podemos reconhecer o teatro, pois "o contemporâneo é aquele que fixa o olhar sobre seu tempo, não para perceber as luzes, mas a obscuridade" (AGAMBEN, 2009, p.28, tradução do autor).

Não seriam dessas obscuridades que falamos? Não seriam tais obscuridades que desejamos? Não seriam elas que nos trazem os momentos de intensidade ao contemplarmos a cena brasileira contemporânea?

\section{Referências}

AGAMBEN, Giorgio. Qu'est-ce que le contemporain? In: AGAMBEN, Giorgio. Nudités. Paris: Éditions Payot \& Rivages, 2009, p.22-43.

AZEVEDO, Sonia Machado. O corpo em lugares e tempos pós-dramáticos. In: GUINSBURG, Jacó; FERNANDES, Silvia (Org.). O pós-dramático. São Paulo: Perspectiva, 2009, p.128150.

BULHÕES-CARVALHO, Ana Maria de. Da Cena ao texto: configurações da teatralidade. In: CARREIRA, André; BIÃO, Armindo; TORRES NETO, Walter Lima. Da Cena Contemporânea. Porto Alegre: ABRACE, 2010, p.180-187.

COHEN, Renato. Performance como linguagem. São Paulo: Perspectiva, 2011.

FERNANDES, Silvia. A encenação. In: FARIA, João Roberto. História do Teatro Brasileiro. Tomo 2: Do modernismo às Tendências Contemporâneas. São Paulo: Perspectiva, 2013, p. 332-370.

FERNANDES, Silvia. Teatralidades Contemporâneas. São Paulo: Perspectiva, 2010.

FISCHER, Stela. Processo Colaborativo e Experiências de Companhias Teatrais Brasileiras. São Paulo: Hucitec, 2010.

FOUCAULT, Michel. L'archéologie du Savoir. Paris: Gallimard, 1969.

GRUZINSKI, Serge. La pensée métisse. Paris: Fayard, 1999.

GUINSBURG, Jacó; PATRIOTA, Rosangela. Teatro Brasileiro: ideias de uma história. São Paulo: Perspectiva, 2012. 
GUMBRECHT, Hans Ulrich. Éloge de la Présence. Ce qui échappe à la signification. Paris: Libella - Maren Sell Éditeurs, 2010.

ICLE, Gilberto. Estudios da la Presencia: del trabajo del actor a la investigación no interpretativa, Telondefondo, Buenos Aires, v. 16, p. 189-204, 2012b, acessível em http:// www.telondefondo.org

ICLE, Gilberto. Estudos da Presença: prolegômenos para a pesquisa das práticas performativas, Revista Brasileira de Estudos da Presença, Porto Alegre, v. 1, p. 9-27, 2011, acessivel em http://seer.ufrgs.br/presenca/article/view/23682/13690.

ICLE, Gilberto. Études de la présence : pour une approche non interprétative du processus de création des pratiques performatives brésiliennes, Cultures-Kairós. Revue des pratiques corporelles et des arts vivant, Saint-Denis, v. 1, p. 1-15, 2012a, acessível em http://revues. mshparisnord.org/cultureskairos.

LAPLANTINE, François. L'art brésilien de la ginga: marcher, danser, chanter. In: LAPLANTINE, François. Le social et le Sensible. Introduction à une anthropologie modale. Paris: Téraèdre, 2009, p.19-34.

LAPLANTINE, François; NOUSS, Alexis. Le Métissage. Sans ville: Flammarion, 1997.

LEHMANN Hans-Thies. Le Théâtre Postdramatique. Paris: L'Arche, 2002.

LISBOA, Eliane. Usina do Trabalho do Ator: reconhecimento de uma identidade. Revista Brasileira de Estudos da Presença, Porto Alegre, v.2, n.2, p. 479-501, jul/dez. 2012. Disponível em: <http://seer.ufrgs.br/presenca/article/view/30132/21105>.

MASSA, Clóvis Dias. A Antropofagia da Usina do Trabalho do Ator. Revista Brasileira de Estudos da Presença, Porto Alegre, v. 2, n. 2, p. 502-515, jul./dez. 2012. Disponível em: http://www.seer.ufrgs.br/presenca.

NIETZSCHE, Friedrich. Vontade de Potência. Rio de Janeiro: Ediouro. [s.d.].

PEREIRA, Marcelo de Andrade. Usina do Trabalho do Ator: (des)caminhos da criação. Revista Brasileira de Estudos da Presença, Porto Alegre, v. 2, n. 2, p. 516-531, jul./dez. 2012. Disponível em: http://www.seer.ufrgs.br/presenca.

PRADIER, Jean-Marie. L'ethnoscénologie. Vers une scénologie générale. L'Annuaire Théâtral : revue québécoise d'études théâtrales, Montreal, n² 29, 2001, p. 51-68.

PRADIER, Jean-Marie. La Scène et la Fabrique des Corps. Ethnoscénologie du spetacle vivant en Occident. Bordeaux: Press Universitaires de Bordeaux, 1997.

RAMOS, Luiz Fernando. Hierarquias do Real na Mímesis Espetacular Contemporânea. Revista Brasileira de Estudos da Presença. Porto Alegre, v.1, n.1, jan./jun.2011, p. 61-76.

RUFFINI, Franco. Stanislavskij e o teatro laboratório, Revista da Fundarte. Montenegro, v.4, n.4, jul./dez. 2004, p.04-15.

SCHECHNER, Richard. Performance Studies, na introduction. New York: Routledge, 2002.

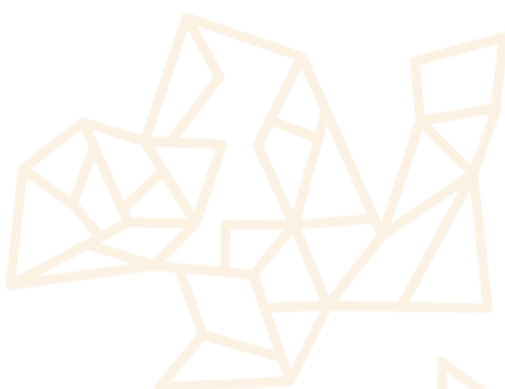

